\title{
Types of absence from work and wages of young workers with apprenticeship training
}

\author{
Astrid Kunze $^{*}$
}

\begin{abstract}
This paper explores the short-and long-term effects on wages of absence from work for young highly attached skilled male and female workers in West Germany. The analysis distinguishes different types of career absence: unemployment, maternity leave for female workers, compulsory service for male workers and other non-work spells. We find negative effects for all types of work absence, except for compulsory service for men. Compulsory service has a positive short-term wage effect. Unemployment decreases wages in the short term only, and for women more strongly than for men. Maternity leave leads to substantial losses for women. An important finding of this study is that maternity leave leads to substantially higher wage losses than other types of work absence, especially in the long term.
\end{abstract}

Keywords: Wages, Human capital, Gender, Unemployment, Maternity leave, Military service, Panel data

JEL Classification: H4, J16, J18, J3, J62, J64, J78, M51

\section{Introduction}

Both men and women experience episodes during their working careers where they are absent from work. During the early career, such episodes are likely to be observed for three main reasons. Unemployment after the loss of a job is particularly frequent for young workers, as international data on unemployment rates show. Work absenteeism is also likely to occur because of parental leave related to childbirth; parental leave is traditionally taken by women. Family formation is started most often before age 30 , which coincides with the early career. In many countries, young men face the risk of compulsory service in the military that also leads to periods of work absence. Given that the early career is an important phase of wage growth but the nature of work absences is quite heterogeneous, questions arise regarding whether work absences affect wages and whether effects vary across types of work absence.

This paper investigates the impact of periods of work absence on wages for young skilled highly attached female and male workers using data for West Germany. The emphasis is on the estimation of the short- and

\section{${ }^{*}$ Correspondence: Astrid.Kunze@nhh.no}

NHH Norwegian School of Economics, Helleveien 30, 5045 Bergen, Norway long-term effects of different types of work absence. The data that we use allow us to distinguish different types of career absence: unemployment, maternity leave for female workers, compulsory service for male workers, and an additional residual group of other non-work spells. For the empirical analysis of the wage determination process, we adopt a panel wage regression building on the human capital model that segments the work history into work experience spells and non-work spells (Mincer and Polachek 1974). We present estimates separately for men and women that take into account heterogeneity in the type of work absence and the timing. The regressions control for how many years have lapsed since the event occurred. We allow for unobserved individual fixed effects.

We focus on workers with apprenticeship training, whom we refer to as skilled workers. Our analysis excludes unskilled workers and those with technical college or university degrees. Typically, an apprenticeship is started after 9 or 10 years of schooling. While in training, apprentices have an apprenticeship employment contract. Training takes $2.5-3.5$ years depending on the training occupation. Firms have to follow national training curricula, and apprentices attend vocational schools for 1-2 days a week. The apprentice is awarded a certificate after successful completion of regionally unified 
oral, written and practical examinations. Apprentices receive a low wage, of about $20-30 \%$ of the wage of a skilled worker. We restrict the sample to highly attached full-time workers in order to exclude workers who drop out of work during the early career. The data sample is extracted from the IABS 75-97. It is particularly suited for the analysis of the relation between episodes of work absence and wages in a human capital framework primarily for three reasons. First, the data allow us to observe for each individual complete wage and employment histories from first entry into employment. Hence, we can measure the human capital accumulation process very accurately. Second, start and end dates of employment and types of work absence throughout the year are available in the event history data set. This allows us to measure the duration of every spell and the type of work absence. Third, the IABS 75-97 allows us to follow a large sample of individuals for a period of up to 15 years or the entire early career. It contains very accurate information on daily wages for full-time workers, as well as detailed information on education that allows us to select workers with apprenticeship training.

The structure of the paper is as follows. Section 2 summarizes previous findings on gender differences and wage effects of different types of work absence. Section 3 reviews the wage regression model that we employ in the empirical analysis. Section 4 presents the data and summary statistics. Section 5 presents the estimation results. Section 6 concludes.

\section{Previous findings on gender differences}

Many studies have investigated gender differences and the effects on wages of working and work absence from a human capital perspective. These studies differ with respect to the wage equation specifications and estimation methods. In a study using the PSID, Kim and Polachek (1994) estimate the effects of contemporaneous accumulated work experience and accumulated home time, which is their measure of total years of work absence. From their less intermittent samples, Kim and Polachek (1994) estimate a loss from home time of between 2 and 13\%/year. Albrecht et al. (1999) use Swedish survey data and estimate wage regressions that contain variables for more specific types of work absence. These are parental leave, household time, other time out of work, unemployment and military service. Their estimates from individual fixed-effects models show that an additional year of time out of work decreases the wages of women by $1.9 \% /$ year and the wages of men by $2.5 \%$ year. For women, losses are larger from unemployment, $4.4 \%$, than from parental leave, $1.8 \%$. For male workers, losses are larger from unemployment, $16 \%$ /year (i.e., $1.3 \% /$ month), than from parentalleave, $6.8 \%$. The strong negative effect of parental leave for men stands out in comparison with the moderate negative effect for women. The authors interpreted the result for fathers as an effect through signalling. As only a few fathers take parental leave, it is a signal of low career commitment. By contrast, virtually all mothers in Sweden take parental leave. They also found that men gain from military service, 4.8\%/year. Light and Ureta (1995) analyse the wage effects of the timing of work and non-work spells and gender differences. They showed significant time patterns of the effects of total time out of work on wages. They found that about $20-30 \%$ of the overall gender gap in years of work experience can be explained by male-female differences in the timing of work histories. Short-term losses from employment interruptions are high, 13\%/year, but become insignificant in the long term, if they occurred more than 2 years ago. The wage regressions that we estimate take account of differences in the effects of types of work absence similar to Albrecht et al. (1999) and timing of employment and work absences, as in Light and Ureta (1995).

A number of studies have focused on the short- and long-term effects of unemployment, and youth unemployment, on wages. The concern is whether scarring exists, particularly for young workers. Scarring occurs if unemployment has permanent negative effects on wages. Several studies have found evidence of scarring effects, but the amount varies widely. Some studies report wage losses of up to $14 \%$ /year, and the time patterns vary substantially (Gregory and Jukes 2001; Arulampalam et al. 2001; Arulampalam 2001; Gregg and Tominey 2005; Nilsen and Reiso 2011). ${ }^{1}$ For male skilled workers graduating from apprenticeship training in the period 19781980 in Germany, Möller and Umkehrer (2015) find negative and long-lasting wage effects from unemployment during the early career. ${ }^{2}$

Wage effects of parental leave have mainly been investigated for women. The focus in these studies has been on whether parental leave decreases wages and whether there are rebound effects in wages following childbirth (Mincer and Ofek 1982). A significant negative wage effect of leave related to childbirth is found for the United States (Anderson et al. 2002; Budig and England 2001; Waldfogel 1998), for the United Kingdom (Joshi et al. 1999; Viitanen 2014), and for Canada (Phipps et al. 2001). No effect is found for Denmark (Gupta and Smith 2002; Nielsen et al. 2004) or for Sweden (Albrecht et al. 1999). For West Germany, losses are relatively

\footnotetext{
${ }^{1}$ For further reviews, see Kletzer and Fairlie (2003) and Kuhn (2002).

${ }^{2}$ In contrast to their study, we include both men and women, and also include apprentice cohorts after 1980. We find no evidence of scarring effects.
} 
large, 10-20\%, for full-time workers (Ejrnæs and Kunze 2013; Ondrich et al. 2003; Schönberg and Ludsteck 2014; Beblo et al. 2009; Görlich and de Grip 2009). In these studies, evidence on rebound effects is mixed. Buligescu et al. (2009) find significant rebound effects, but Ejrnæs and Kunze (2013) find only a slight recovery of wages following first leaves. Other evidence suggests that postponement of childbirth leads to relative increases in wages because the returns to experience are relatively large before entry into motherhood (Miller 2011). The model by Polachek (1981) predicts that a direct link exists between human capital depreciation and occupational choice, and the gendered occupational segregation in labour markets. If women expect more interrupted working careers than men, then women are expected to sort into occupations with relatively flat wage-experience profiles. Under this choice, they maximize their lifetime earnings. The hypothesis follows that female-dominated occupations are characterized by relatively low depreciation rates because of work absence, and parental leave particularly. Empirical evidence is, however, quite mixed. For example, Polachek (1981) and Görlich and de Grip (2009) confirm the hypothesis, but England (1982) contradicts it.

In many countries, men have to undertake military service. The direction of the effect on mens' wages is unclear from economic theory, and only if military service carries general skills that can be transferred to other civil jobs can we expect positive effects. The international evidence has been quite mixed on the direction of the wage effect. Bauer et al. (2012) find no significant wage effects for German conscripts. In an earlier paper by Acemoglu and Pischke (1998), a positive and significant wage effect is found directly after military service. Their study uses a sample of apprentices graduating in Germany before the early 1980s. Their results also show negative effects on having ever served in the military. Card and Cardoso (2012) find a significant and positive impact of 4-5\% points on the wages of men with only primary education in Portugal. The effect is zero for men with higher education. In this study, we explore the wage effects of different types of work absence varying across gender in an integrated framework.

\section{The wage regression and absence from work}

We estimate logarithmic wage regressions that build on the Mincerian earnings regression (Mincer 1974), but we break up the post-schooling period into successive segments of participation and non-participation (Mincer and Polachek 1974). In addition, we distinguish shortterm and long-term effects by taking into account the timing of the periods of work absence. Specifically, effects are allowed to vary depending on how many years have lapsed since the event occurred. ${ }^{3}$ The wage regression is written as follows:

$$
\begin{aligned}
\operatorname{lnw}_{i t}= & \beta_{0}+\sum_{s=t}^{s=t-6} \operatorname{ex}_{i s} \beta_{1 s}+\sum_{s=t}^{s=t-6} \mathrm{ue}_{i s} \gamma_{1 s} \\
& +\sum_{s=t}^{s=t-6} \operatorname{ir}_{i s} \gamma_{2 s}+\sum_{s=t}^{s=t-6} \mathrm{nw}_{i s} \gamma_{3 s}+v_{i}+u_{i t}
\end{aligned}
$$

where $i$ indexes individuals and $t$ is time. The dependent variable is the logarithmic real daily wage, lnw. The vector ex includes the variable work experience, and $\mathrm{ue}_{i t}$ stands for unemployment, $\mathrm{ir}_{i t}$ for interruptions because of compulsory service or maternity leave and nw for nonwork. $v_{i}$ is an unobserved individual specific effect, and $u_{i t}$ is idiosyncratic noise.

We measure the variables for work experience by the percentage of the previous year spent in employment, 1 year ago, 2 years ago, etc. The coefficients of the work experience variables can be interpreted as the return to an additional year of work experience in the respective year on current wages. Spells of absence from work are not frequent in individual employment histories and are often short; for example, in the case of unemployment. We attempt to test whether the incidence of a spell of work absence affects wages and whether the effect varies across types of absences. Therefore, we define dummy variables that are equal to one if an individual has had a spell of unemployment, non-work or interruption in the current or previous year, 1 year ago, or 2 or more years ago. These are the variables that we include in the wage regression. The coefficients of the types of absence from work variables measure the marginal effect of the incidence of unemployment, interruption or non-work. Across a calendar year, the proportion of the year in work and absent from work would add to one and possibly introduce multicollinearity problems; therefore, it is not straightforward to estimate the marginal effects in terms of the duration of work absence for each year. Within the human capital framework, the coefficients are interpreted as net returns during work and net depreciation rates due to the incidence of work absence.

We estimate Eq. (1) by individual fixed effects accounting for the potential correlation of unobserved individual specific effects with the work history variables and log wages. Unobserved individual-fixed but time-invariant factors may capture ability that is not observed in the data and that is also difficult to measure, and other

\footnotetext{
${ }^{3}$ In the empirical analysis, we assume that the coefficients vary up to 6 years ago; hence, they are equal for 6, 7 or more years ago. Statistical tests that we conducted with our data tend to show that marginal effects longer into the past do not vary significantly.
} 
individual unobserved fixed characteristics at first entry, such as training occupation or pre-labour market characteristics, that we do not explicitly control for in the wage regressions. The estimation approach also accounts for non-random selection on individual fixed factors. As we control for the lagged terms in the segmented work history model, we control for heterogeneity. Our focus is on investigating the differences across types of absences for men and women separately, as well as differences across men and women in the coefficients of specific types of absence variables.

We present the estimation results for women and men separately. We test the robustness of our results and extend our results in two directions. We present estimation results where the coefficients are allowed to vary across two main occupational groups: female-dominated occupations, and integrated or male-dominated occupations. In addition, we estimate models where the coefficients of the work absence variables are allowed to vary depending on whether individuals change firms when they re-enter employment after the work absence, or not.

\section{Data and summary statistics}

We extract a sample of young skilled highly attached workers from the IAB employment sample (IABS) for West Germany for the period 1975-1997 (IABS 75-97). ${ }^{4}$ The IABS $75-97$ is a $1 \%$ random sample drawn from the event history data file of the social security insurance scheme; these are the employment statistics collected by the German Federal Bureau of Labour. They contain all dependent employees in the private sector; i.e., about $80 \%$ of total employment in Germany. Not included are: civil servants, self-employed, unpaid family workers and people who are not eligible for benefits from the social security system. The register data are of high quality, because of the accuracy of both the wages (which are based on taxable income) and the employment history data. The IABS 75-97 contains approximately 200,000 individuals from every cross-section of the panel.

We focus on workers who have received apprenticeship training. We identify skilled workers by their duration of training within a firm as well as the qualification status that is reported in the IABS 75-97; we identify those who switch from unskilled to skilled work after the completion of training. We include all workers who have one consecutive period of training that is longer than 450 days. Those who undertake more than one apprenticeship are excluded. We also exclude workers who have earned a degree from a technical college or university after or before training. In order to capture the main group of

\footnotetext{
${ }^{4}$ IABS is the abbreviation for the Institut für Arbeitsmarkt und Berufsforschung Sample. For a more detailed data description on an earlier release of the data set, see Bender et al. (2000).
}

skilled workers who typically start training early, we drop workers who started their first job after training relatively late; that is, later than age 25 . We focus on full-time workers and exclude workers who have ever worked part-time or fewer than $35 \mathrm{~h} /$ week. Although hours of work are generally an important explanatory factor of the gender wage gap, focusing on full-time workers eliminates differences in average hours, as Kunze (2005) finds. We restrict the analysis sample to individuals who have been employed as a skilled worker for at least two spells after training and were working from age $26-30$. While this age range is a somewhat arbitrary choice, it is a typical age range where women drop out of work because of childbirth and childcare at home. Overall, by applying these sample selection rules to both men and women, we select a sample of skilled highly attached workers. We use the period 19811997 for the empirical analysis. The final sample contains approximately 17,000 individuals observed in at least two full-time working spells after completion of vocational training, and approximately 220,000 spells: 78,000 spells for women and 163,000 spells for men.

The main variables for our analysis are wage, work experience and four types of work absence. The wage variable measures the daily wage in an employment spell after training and is defined as the logarithm of daily gross wages deflated by a standard CPI index for Germany. ${ }^{5}$ Wages refer to the main job.

Work experience is calculated by accumulating days of full-time work for each individual. ${ }^{6}$ We transform the variable into years of full-time work experience. The types of absence from work variables that we use are unemployment, interruptions because of maternity or parental leave for female workers (in the following referred to as maternity leave), interruptions because of military/civil service for male workers, and other non-work spells. ${ }^{7}$ In the IABS 75-97, we can directly identify unemployment spells and when individuals transition from employment status with wage payment into employment status without wage payment. This is work absence because of an interruption of work. ${ }^{8}$ The way that we construct our sample and variables is crucial for the way that we interpret the reasons for

\footnotetext{
${ }_{5}^{5}$ Generally, in the IABS, wages are top-coded. This, however, does not imply problems for our sample of young skilled workers. None of the wage spells are top-coded.

${ }^{6}$ Individual records in the IABS are organized in spells with start and end dates, which are not longer than 1 year. A spell is reported for every change related to the employment and non-employment status. From the dates and information on employment status, we generate a variable for actual experience.

7 The duration of non-work is measured by the duration of a gap in the data records.

${ }^{8}$ In the IABS 75-97, we use the type variable to define employment status. Interruptions are counted if the previous spell is an employment spell with wage payment.
} 
interruptions for men and women. A challenge is that we do not directly observe childbirth, maternity leave or military/civil service as a working status in the IABS 75-97 data. Crucial for our approach is that we focus on young skilled highly attached workers for whom we observe complete work histories from first entry.

The claim of unemployment benefits is conditional on the claimant being unemployed and being registered as such at the employment office. Duration of claims for unemployment insurance are stated in the Arbeitsfö rderungsgesetz (employment law) in 1969 and subsequent amendments, and depend on the duration of work in a job for which social insurance is compulsory. Independent of the year of the amendment of the law, workers younger than 42 years can claim unemployment insurance for up to a maximum of 12 months. After that period, an unemployed person may be eligible for unemployment assistance. In the IABS 75-97 data, we cannot directly observe whether an individual is registered as unemployed; therefore, we use the information on the duration of the receipt of unemployment benefits and unemployment assistance together with the calendar year of receipt. This gives us a precise measure of the start of the unemployment benefit receipt. ${ }^{9}$ We acknowledge that in some cases, this may lead to underestimation of the duration of unemployment. ${ }^{10}$ We report estimates of the effect of the incidence of unemployment benefit receipts on wages. In addition, we allow the marginal effect to vary depending on how much time has passed since the incidence of unemployment.

For all men living in Germany and older than 18, military service was compulsory in our observation window. ${ }^{11}$ Usually, men are drawn into national service at the age of 19 . However, men cannot serve before the age of $17,{ }^{12}$ and men cannot be drawn into military service after the age of 25 (in exceptional cases, 28). National service in Germany was compulsory in the form of military service (Grundwehrdienst) or civil service, but because of bad health, men could be released from service completely. ${ }^{13}$ Military service was

\footnotetext{
${ }^{9}$ In the literature, the common approach is to use the total non-employment period as a measure of unemployment; see, e.g., Schmieder et al. (2012).

10 For example, unemployment assistance may not be paid until the end of an unemployment period because it is means tested.

11 See: Wehrdienst-Kriegsdienstverweigerung-Zivildienst. in: Presse-und Informationsamt der Bundesregierung Referat Aussen-, Sicherheits-und Europapolitik, Feb. 1996. Since 2011, which is long after the observation window of our data sample, military service has no longer been compulsory for men older than 18 in Germany.

12 Before the age of 17 , military service can be served only with the consent of the parents.

13 Omitting controls for health could induce bias when we estimate the wage effect of compulsory service because those with bad health are less likely to serve. We account for this potential bias through individual fixed effects.
}

15 months until 1989, when it was reduced to 12 months. Civil service took one-third longer. ${ }^{14}$ Compulsory service implies the right to return to the previous firm and job, unless it was a fixed-term contract. In the data, we use work interruptions to construct variables measuring the incidence and the duration of military/civil service. The IABS 75-97 does not contain a variable listing the particular reason for the interruption. Potential reasons are maternity leave, long illness, disability, full-time education and military/civil service. ${ }^{15}$ However, we can credibly exclude that interruptions are reported because of parental leave and full-time education in our sample for men. This is because of the way that we selected young highly skilled men and constructed the work absence variables. We acknowledge that we cannot completely rule out the possibility that a few spells of disability and sickness are contained in our measure; however, these are unlikely to affect our mean results on young men. ${ }^{16}$ We cannot distinguish military service from civil service in the data. We know from another study that civil servants in community services account for approximately $30 \%$ of all draftees that have not been exempt (Trabold et al. 2006). This figure is for the birth cohorts 1962-1977 that are close in age to the men in our analysis sample. In the regression analysis, we use the incidence of military/civil service within a year and therefore estimate the wage effect, unweighted by the duration. We estimate short- and long-term effects. We interpret the interruption in the work history for young skilled men as a result of the incidence of compulsory service, either military or civil service.

We summarize the duration of maternity leave and parental leave for women in one variable, which is referred to as maternity leave in the following. For the interpretation of the results, it is important to note that the variable is bounded upward. Until 1986, the maximum duration of leave was 6 months by law; in 1988, it was extended to 12 months, in 1990 to 18 months, and since 1991, it has been 3 years. The interesting feature of maternity leave is that within the maximum period of

\footnotetext{
${ }^{14}$ During military service, men receive a very low compensation, which is below the wage of an unskilled worker.

15 This list of reasons is from the pension data. The study by Bauer et al. (2012) estimates the effect of military service on earnings and uses information on interruptions in the IABS merged with additional information on the reason for the interruption from pension data. We do not have access to this additional information.

16 We have run several descriptive tests in order to investigate how reliably our interruption of work variable measures military/civil service. For example, we used institutional knowledge and compared the observed mean duration with the duration of military/civil service by law in a given year. In Table 1, we report the means of observed duration of work interruption because of military/civil service, which is 0.3 across all observations and a bit higher at 0.37 across all individuals with a non-zero duration of total time out of work. Trabold et al. (2006) report that less than 60\% undertake compulsory service.
} 
Table 1 Summary statistics for early career

\begin{tabular}{|c|c|c|c|}
\hline & $\begin{array}{l}\text { Female sample } \\
\text { Mean (std.) }\end{array}$ & $\begin{array}{l}\text { Male sample } \\
\text { Mean ( std.) }\end{array}$ & Diff. in means \\
\hline & Total sample & & \\
\hline Age & $32.4396(2.0984)$ & $32.9277(2.1901)$ & $-.4881^{\mathrm{b}}$ \\
\hline Full-time (FT) work experience & $10.2313(3.2503)$ & $10.5538(3.2828)$ & $-.3224^{b}$ \\
\hline Maternity leave & $.2583(.5092)$ & & \\
\hline Compulsory service ${ }^{a}$ & & $.3107(.4652)$ & \\
\hline Unemployment & $.3176(.8142)$ & $.5125(1.0655)$ & $-.1949^{b}$ \\
\hline Non-work & $.8834(1.9737)$ & $1.0904(1.8552)$ & $-.2070^{b}$ \\
\hline Tme out of work & $1.4593(2.4335)$ & $1.9137(2.2815)$ & $-.4543^{b}$ \\
\hline \multirow[t]{2}{*}{ \# of indiv. } & 5753 & 11,000 & \\
\hline & Sample excluding spells with zeros in time out of work variable & & \\
\hline Age & $32.5548(2.1042)$ & $32.9740(2.1973)$ & $-.4192^{\mathrm{b}}$ \\
\hline Full-time (FT) work experience & $9.6449(3.3703)$ & $10.3131(3.3374)$ & $-.6681^{b}$ \\
\hline Maternity leave & $.4166(.5935)$ & & \\
\hline Compulsory service & & $.3740(.4867)$ & \\
\hline Unemployment & $.5122(.9846)$ & $.6170(1.1411)$ & $-.1047^{b}$ \\
\hline Non-work & $1.4248(2.3478)$ & $1.3126(1.9625)$ & $.1121^{\mathrm{b}}$ \\
\hline Time out of work & $2.3537(2.7289)$ & $2.3037(2.3168)$ & .0500 \\
\hline \# of indiv. & 3567 (62\%) & $9138(83 \%)$ & \\
\hline
\end{tabular}

Data: 1981-1997 IABS data. Variables are measured at the last wage (working) spell. All variables are measured in years

${ }^{\text {a }}$ Compulsory service can be military or civil service

b Significant at 5\% level

maternity leave, the parent has the right to return to the same firm (job protection).

Maternity leave can be measured in the data only for young women. In general, an interruption is reported in the IABS 75-97 data when someone is employed and the employment contract is on hold; in this case, the employer does not pay the wage. This category applies in case of job-protected maternity leave and military/civil service (which is not relevant for women) as well as long sickness leave. We assume that the latter is negligible for young skilled women, and maternity leave is the only relevant reason when an interruption occurs.

The assumption regarding maternity leave was first used in Ejrnæs and Kunze (2006). Schönberg (2009) tests and confirms the assumption for young women who are attached to the labour market, in terms of working just until the start of maternity leave. ${ }^{17}$ Hence, the data are

\footnotetext{
${ }^{17}$ Schönberg (2009) uses the IABS 75-95, which is similar to the IABS 75-97, in order to test the assumption that interruptions for young attached women measure parental leave related to childbirth. It is confirmed that $90 \%$ of women who were working just before the interruption did in fact take maternity leave. She can relate, after some restrictions, $90 \%$ of all leave spells to childbirth. This number refers to all age groups, whereas we focus on young women where the proportion is substantially higher. Schönberg (2009) concludes that the IABS is useful if the research focus is on women who are attached to the labour market. In $70 \%$ of all leave cases the correct child's month of birth can be inferred from the start of the leave spell in the social security data.
}

also rich in terms of the timing of maternity leave. ${ }^{18} \mathrm{We}$ present mean estimates of the marginal effect of the incidence of maternity leave; we estimate the wage effect of maternity leave spells during the current year, 1 year ago, and 2 or more years ago.

In Table 1, we present the summary statistics of all the work history variables. Means and standard deviations are calculated at the last employment spell in every individual time series and reported separately for women and men. In addition, the table reports the differences in means together with significance levels. As we see for the total sample, we follow the workers until they are on average 32 years old; women are half a year younger. By this time, male workers collected slightly more full-time work experience than women; even though the difference is significant, it is small. They also accumulated more time out of work. Male workers were unemployed for approximately 0.2 years longer than women. In the lower part of Table 1, we report means for those who had for any reason at least one spell of work absence during the observation window. Eighty-three per cent of men had

\footnotetext{
${ }^{18}$ There might be a small measurement error in the duration variable. As we do not use the duration of maternity leave directly in the final wage regressions but only the incidence throughout a calendar year, measurement error should not bias our results.
} 
at least one work absence spell. Among female workers, the incidence is $62 \%$. The descriptive statistics show that absence from work during the early labour market career is important for both men and women.

\section{Estimation results}

In this section, we present the estimation results of the wage regressions specified in Eq. (1) for men and women. We allow for up to six lags in the regressions of the segmented work history model. We present the estimated coefficients from individual fixed-effects models. ${ }^{19}$ This means that we can interpret the coefficients as the marginal effects holding constant individual specific timeinvariant factors, such as ability, as well as other individual unobserved fixed characteristics at first entry, such as training occupation or pre-labour market characteristics. ${ }^{20}$

The estimation results are presented in Table 2 for women and Table 3 for men. For comparison, column 1 contains the estimation results of a standard quadratic wage regression model. We find increasing returns at a decreasing rate, for both men and women, as is common in previous studies. The coefficients of the work absence variables are negative, except for non-work and compulsory service for men. In column two of Table 2 for women and Table 3 for men, respectively, we report the main estimation results of the work history model estimated on the entire sample. The hypotheses of equality of the coefficients in the work history model across time segments and for the same type can be rejected at the 5\% significance level for both the female and male sample regressions. This also holds for the work experience variables. ${ }^{21}$ The returns to work experience are positive for both male and female workers. For women, the return from an additional year of experience gained during the current year or 1 year ago is 8.4 and $7.1 \%$ respectively. The corresponding returns are 7.2 and $5.6 \%$ for men. Human capital accumulated up to 6 years ago raises wages by $3.9 \% /$ year for women, and $2.1 \%$ for men. It seems likely that positive selection of women participating in the labour market explains the somewhat higher return to work experience for women compared with men. ${ }^{22}$ This is positive selection that is not accounted for by individual fixed and time-invariant effects. This bias

\footnotetext{
19 The Hausman test statistic rejects the random effects model. The Hausman test statistic is $\chi^{2}(44)=897.68$ for the pooled female sample regression, and $\chi^{2}(44)=1181.01$ for the male sample.

${ }^{20}$ Other studies have shown the explanatory power of entry characteristics for entry wages (e.g., Göggel and Zwick 2012).

21 The F-statistics (p values) for the test of equality of coefficients are reported in column 2 of Tables 2 and 3.

${ }^{22}$ Using a Welch t test, we find that the coefficients are highly significantly different across gender.
}

may be somewhat increased in the work history model estimated by fixed effects because more weight is given to more continuously working women.

This seems to be confirmed when we look at the predicted wage-experience profiles in Figs. 1 and $2 .^{23}$ Entry wages and the other controls are normalized to zero in the figures. For the sample of male workers, estimates from both models are very similar. By contrast, for female workers, the work history model predicts relatively higher wages. At 10 years of accumulated work experience, the difference is approximately $20 \%$.

The estimation results for female workers on work absences show clearly that the wage effect of a spell of work absence is negative for any type of work absence. This means that for women, a work absence is followed by a decrease in wages at the mean wage. Notably, the size of the wage loss varies across types and time lags. Losses from unemployment appear to be relatively small and insignificant in the long term. Unemployment during the most recent year decreases wages on return by $1.9 \%$. We do not find any "scarring" effects in the sense that unemployment in the past affects wages. This shows that those skilled workers who return to a job manage to catch up rather quickly. ${ }^{24}$ The non-work variables have significant negative coefficients for up to five years into the past. Recall, that the non-work variable summarizes the residual group of those who are not working. Hence, here we find negative effects that are long-term and a decrease at a declining rate. The loss decreases from $4.7 \%$ on return to the job, to $1.7 \%$ when the spell of non-work is 5 years ago.

The effects of maternity leave through work absence are significantly larger by comparison. The marginal effect of maternity leave during the current year is $18.3 \% .{ }^{25}$ Controlling for overall full-time experience, the wages of women just returning from maternity leave are $18.3 \%$ lower than the wages of women who were not on maternity leave in the previous year. If the interruption was 2 years ago, the gap is $14 \%$, and after 5 years or longer, it is $13 \%$. These estimates suggest that the effects are very large and long-lasting. The pattern also suggests a rebound effect, although a small one, after maternity leave. This is because the wage loss related to maternity leave declines gradually. The wage loss decreases by $4-5 \%$

\footnotetext{
${ }^{23}$ Because in the quadratic model the variables for time out of work are only included linearly in years, a direct comparison of the two models is difficult.

24 This seems to contrast with the findings that are consistent with scarring by Gregory and Jukes (2001) for the UK and Möller and Umkehrer (2015).

${ }^{25}$ Note that the coefficients are estimated very precisely, and the coefficients of the maternity leave variables are significantly different from the coefficients of the other work absence variables.
} 
Table 2 Fixed effects estimates of wage equations, 1981-1997 IABS data female young workers

\begin{tabular}{|c|c|c|c|c|}
\hline \multirow[t]{3}{*}{ Variables } & \multicolumn{2}{|l|}{ Quadratic model } & \multicolumn{2}{|c|}{ Segmented work history model ${ }^{\mathrm{a}}$} \\
\hline & \multirow[t]{2}{*}{ Coef. (t value) } & \multirow[t]{2}{*}{ Coef. (t value) } & \multirow{2}{*}{$\begin{array}{l}\text { Female occupations } \\
\text { Coef. (t value) }\end{array}$} & \multirow{2}{*}{$\begin{array}{l}\text { Integrated/male occupations } \\
\text { Coef. (t value) }\end{array}$} \\
\hline & & & & \\
\hline FT experience (years) & $0.0499(16.52)^{* *}$ & & & \\
\hline FT experience squared & $-0.0021(43.97)^{* *}$ & & & \\
\hline \multicolumn{5}{|l|}{$\%$ of year spent working } \\
\hline$<1$ year ago & & $0.0847(10.32)^{* *}$ & $0.0776(8.59)^{* *}$ & $0.0793(4.43)^{* *}$ \\
\hline 1 year ago & & $0.0718(21.21)^{* *}$ & $0.0704(19.94)^{* *}$ & $0.0603(6.63)^{* *}$ \\
\hline 2 years ago & & $0.0669(20.00)^{* *}$ & $0.0688(19.69)^{* *}$ & $0.0435(4.94)^{* *}$ \\
\hline 3 years ago & & $0.0618(18.33)^{* *}$ & $0.0643(18.26)^{* *}$ & $0.0324(3.70)^{* *}$ \\
\hline 4 years ago & & $0.0506(14.86)^{* *}$ & $0.0546(15.36)^{* *}$ & $0.0316(3.61)^{* *}$ \\
\hline 5 years ago & & $0.0616(20.84)^{* *}$ & $0.0600(19.39)^{* *}$ & $0.0567(7.31)^{* *}$ \\
\hline $6+$ years ago & & $0.0386(45.38)^{* *}$ & $0.0418(45.11)^{* *}$ & $0.0197(8.22)^{* *}$ \\
\hline Unemployment (years) & $-0.0297(7.75)^{* *}$ & & & \\
\hline \multicolumn{5}{|l|}{1 if in unemployment } \\
\hline$<1$ year ago & & $-0.0193(3.62)^{* *}$ & $-0.0238(4.08)^{* *}$ & $0.0016(0.13)$ \\
\hline 1 year ago & & $-0.0092(1.89)$ & $-0.0089(1.66)$ & $-0.0049(0.46)$ \\
\hline 2 years ago & & $0.0049(0.97)$ & $0.0034(0.61)$ & $0.0154(1.40)$ \\
\hline 3 years ago & & $0.0081(1.55)$ & $0.0105(1.82)$ & $0.0067(0.60)$ \\
\hline 4 years ago & & $-0.0041(0.76)$ & $0.0012(0.20)$ & $-0.0142(1.22)$ \\
\hline 5 years ago & & $0.0007(0.12)$ & $0.0039(0.62)$ & $-0.0072(0.61)$ \\
\hline $6+$ years ago & & $0.0009(0.20)$ & $0.0109(2.24)^{*}$ & $-0.0220(2.20)^{*}$ \\
\hline Non-work (years) & $-0.0380(12.03)^{* *}$ & & & \\
\hline \multicolumn{5}{|l|}{1 if in non-work } \\
\hline$<1$ year ago & & $-0.0475(10.16)^{* *}$ & $-0.0515(9.90)^{* *}$ & $-0.0505(5.17)^{* *}$ \\
\hline 1 year ago & & $-0.0502(12.43)^{* *}$ & $-0.0615(13.79)^{* *}$ & $-0.0390(4.53)^{* *}$ \\
\hline 2 years ago & & $-0.0406(9.79)^{* *}$ & $-0.0488(10.61)^{* *}$ & $-0.0394(4.53)^{* *}$ \\
\hline 3 years ago & & $-0.0296(6.90)^{* *}$ & $-0.0364(7.64)^{* *}$ & $-0.0240(2.70)^{* *}$ \\
\hline 4 years ago & & $-0.0288(6.45)^{* *}$ & $-0.0343(6.94)^{* *}$ & $-0.0167(1.83)$ \\
\hline 5 years ago & & $-0.0172(3.70)^{* *}$ & $-0.0212(4.09)^{* *}$ & $-0.0047(0.50)$ \\
\hline $6+$ years ago & & $0.0059(1.55)$ & $0.0030(0.72)$ & $0.0021(0.25)$ \\
\hline Maternity leave (years) & $-0.3181(72.90)^{* *}$ & & & \\
\hline \multicolumn{5}{|l|}{1 if maternity leave } \\
\hline$<1$ year ago & & $-0.1837(31.39)^{* *}$ & $-0.1899(30.25)^{* *}$ & $-0.1228(8.77)^{* *}$ \\
\hline 1 year ago & & $-0.1766(33.45)^{* *}$ & $-0.1810(32.23)^{* *}$ & $-0.1159(9.12)^{* *}$ \\
\hline 2 years ago & & $-0.1480(26.19)^{* *}$ & $-0.1538(25.50)^{* *}$ & $-0.0842(6.30)^{* *}$ \\
\hline 3 years ago & & $-0.1406(23.02)^{* *}$ & $-0.1446(22.10)^{* *}$ & $-0.0949(6.63)^{* *}$ \\
\hline 4 years ago & & $-0.1447(21.96)^{* *}$ & $-0.1425(20.18)^{* *}$ & $-0.1177(7.76)^{* *}$ \\
\hline 5 years ago & & $-0.1304(18.45)^{* *}$ & $-0.1378(18.16)^{* *}$ & $-0.0735(4.49)^{* *}$ \\
\hline $6+$ years ago & & $-0.1339(26.00)^{* *}$ & $-0.1450(25.91)^{* *}$ & $-0.0647(5.50)^{* *}$ \\
\hline Year dummies & Yes & Yes & Yes & Yes \\
\hline Constant & $4.3840(393.51)^{* *}$ & $4.4757(377.55)^{* *}$ & $4.4890(351.01)^{* *}$ & $4.5352(147.96)^{* *}$ \\
\hline \# observations & 78,009 & 72,679 & 62,997 & 9682 \\
\hline \# individuals & 5753 & 5753 & 4424 & 1329 \\
\hline$R^{2}$ & 0.37 & 0.31 & 0.33 & 0.10 \\
\hline$F(7,66,882)$ for ue & & 3.15 & & \\
\hline$p$ value & & 0.0025 & & \\
\hline$F(7,66,882)$ for ir & & 57.32 & & \\
\hline p value & & 0.0 & & \\
\hline$F(7,66,882)$ for $n w$ & & 448.13 & & \\
\hline
\end{tabular}


Table 2 continued

\begin{tabular}{|c|c|c|c|c|}
\hline \multirow[t]{3}{*}{ Variables } & \multicolumn{2}{|c|}{ Quadratic model } & \multicolumn{2}{|c|}{ Segmented work history model ${ }^{a}$} \\
\hline & Coef. (t value) & Coef. (t value) & Female occupations & Integrated/male occupations \\
\hline & & & Coef. (t value) & Coef. (t value) \\
\hline$p$ value & & 0.0 & & \\
\hline
\end{tabular}

points when we compare the wage effect from a recent leave with a leave longer than 5 years ago.

For the female sample, the comparison of the wage effects of different types of work absences suggests that work absences lead to wage losses consistent with a human capital model allowing for depreciation of human capital. However, we find that the effects vary across types of absence from work. For the relatively young skilled women in our sample, losses in cases of unemployment are the lowest and short-term, somewhat larger but declining in the longer term in cases of non-work and substantially larger for work interruptions capturing maternity leave. Note that extended maternity leave beyond guaranteed leave by law is captured by the variable non-work according to our definitions. Wage losses through maternity leave are declining in the longer term but remain large and negative, and larger than the wage losses related to any of the other types of absence.

As reported in column 2 of Table 3, the results are quite different when it comes to the effects of work absences for men. The negative effect of a spell of unemployment on wages is between 0.2 and $0.5 \%$ and not significant in the short and long term. ${ }^{26}$ While we find that at the mean, women experience a $2 \%$ loss in wages in the short term, men do not. As we control for education, work experience, hours of work and individual fixed effects in both regressions, these estimates are for similar workers. When we look again at the results for men, non-work in the short term leads to a loss of $1.4-1.9 \%$ if the spell occurred during the most recent two years. In the longer term, the loss decreases to $0.6 \%$ but remains significant. Interesting are the findings on the category of work absence that captures work interruptions or compulsory service. We find that a spell of work interruption during the current year leads to a wage gain of $3.2 \%$ on the return to work. If more time has passed since the interruption, the wage effects do not contain a clear pattern. Only in the short term is the effect significant and positive. The size of the effect is quite substantial as it amounts to slightly less than half of the annual return to

${ }^{26}$ The null hypothesis of joint significance is rejected. recent work experience (3.2 compared with 7.2\%). A positive effect is consistent with human capital theory if compulsory service teaches general skills that can be used in the main job as a skilled worker.

In summary, for men we find that types of absences tend to lead to slight declines in wages that are mainly short-term effects. Notably, if the work absence is related to compulsory service, men gain in the short term. Taking the results for men and women together, they show that workers experience positive returns to increases in general human capital, but also slight losses in response to work absence. These results are possibly related to human capital depreciation in the short term. They seem consistent with a human capital model and depreciation of human capital. Findings on the short- and long-term effects of maternity leave for women are quite different from the results for other work absences for women and for men. If decreases in wages capture human capital depreciation, it is not quite clear why depreciation should be larger during maternity leave than during other types of absences.

\subsection{Female- and male-dominated occupations}

It seems striking that we find in the pooled regression for women quite large and negative wage effects related to maternity leave. If these capture mainly the effects through human capital depreciation, we may expect those to be relatively smaller in occupations typically filled by women. Labour markets are generally characterized by strong occupational segregation by gender. A potential explanation is that women select careers with relatively flat earnings profiles where depreciation of human capital is relatively small during periods of leave (Polachek 1981). If women expect to have more interruptive careers and to maximize life cycle earnings, they are more likely to select occupations where they experience relatively low wage losses during periods of leave. We observe that women are more likely to work in services and that men are more likely to work in manual jobs. Examples of typical occupations for female skilled workers observed in our data are professional clerical worker, sales person, receptionist, hygienist, banking professional 
Table 3 Fixed effects estimates of wage equations, 1981-1997 IABS data male young workers

\begin{tabular}{|c|c|c|c|c|}
\hline \multirow[t]{3}{*}{ Variables } & \multicolumn{2}{|l|}{ Quadratic model } & \multicolumn{2}{|c|}{ Segmented work history model ${ }^{a}$} \\
\hline & Coef. (t value) & Coef. (t value) & Female occupations & Integrated/male occupations \\
\hline & & & Coef. (t value) & Coef. (t value) \\
\hline FT experience (years) & $0.0565(30.53)^{* *}$ & & & \\
\hline FT Experience squared & $-0.0018(57.35)^{* *}$ & & & \\
\hline \multicolumn{5}{|l|}{$\%$ of year spent working } \\
\hline$<1$ year ago & & $0.0720(18.97)^{* *}$ & $0.0844(8.07)^{* *}$ & $0.0602(15.34)^{* *}$ \\
\hline 1 year ago & & $0.0562(27.67)^{* *}$ & $0.0727(16.31)^{* *}$ & $0.0468(21.65)^{* *}$ \\
\hline 2 years ago & & $0.0444(22.17)^{* *}$ & $0.0601(13.75)^{* *}$ & $0.0367(17.25)^{* *}$ \\
\hline 3 years ago & & $0.0355(17.63)^{* *}$ & $0.0552(12.64)^{* *}$ & $0.0273(12.75)^{* *}$ \\
\hline 4 years ago & & $0.0314(15.52)^{* *}$ & $0.0534(12.26)^{* *}$ & $0.0214(9.96)^{* *}$ \\
\hline 5 years ago & & $0.0402(22.17)^{* *}$ & $0.0608(15.88)^{* *}$ & $0.0276(14.22)^{* *}$ \\
\hline $6+$ years ago & & $0.0213(39.21)^{* *}$ & $0.0337(26.51)^{* *}$ & $0.0160(26.74)^{* *}$ \\
\hline Unemployment (years) & $-0.0190(9.01)^{* *}$ & & & \\
\hline \multicolumn{5}{|l|}{1 if in unemployment } \\
\hline$<1$ year ago & & $-0.0016(0.63)$ & $-0.0184(2.60)^{* *}$ & $-0.0047(1.76)$ \\
\hline 1 year ago & & $-0.0047(2.02)^{*}$ & $-0.0064(1.00)$ & $-0.0064(2.70)^{* *}$ \\
\hline 2 years ago & & $-0.0021(0.90)$ & $-0.0103(1.60)$ & $-0.0026(1.06)$ \\
\hline 3 years ago & & $-0.0039(1.63)$ & $-0.0088(1.35)$ & $-0.0057(2.32)^{*}$ \\
\hline 4 years ago & & $0.0030(1.25)$ & $-0.0147(2.21)^{*}$ & $0.0029(1.16)$ \\
\hline 5 years ago & & $0.0008(0.34)$ & $-0.0059(0.86)$ & $-0.0011(0.45)$ \\
\hline $6+$ years ago & & $-0.0088(4.50)^{* *}$ & $-0.0182(3.36)^{* *}$ & $-0.0014(0.69)$ \\
\hline Non-work (years) & $0.0118(6.15)^{* *}$ & & & \\
\hline \multicolumn{5}{|l|}{1 if in non-work } \\
\hline Previous year & & $-0.0193(9.41)^{* *}$ & $-0.0093(1.46)$ & $-0.0186(8.96)^{* *}$ \\
\hline 1 year ago & & $-0.0146(8.19)^{* *}$ & $-0.0142(2.84)^{* *}$ & $-0.0132(7.20)^{* *}$ \\
\hline 2 years ago & & $-0.0093(5.16)^{* *}$ & $-0.0138(2.77)^{* *}$ & $-0.0064(3.48)^{* *}$ \\
\hline 3 years ago & & $-0.0074(4.04)^{* *}$ & $-0.0097(1.92)$ & $-0.0039(2.09)^{*}$ \\
\hline 4 years ago & & $-0.0052(2.78)^{* *}$ & $-0.0071(1.39)$ & $-0.0013(0.69)$ \\
\hline 5 years ago & & $0.0017(0.92)$ & $0.0026(0.51)$ & $0.0046(2.36)^{*}$ \\
\hline $6+$ years ago & & $0.0061(3.63)^{* *}$ & $0.0102(2.33)^{*}$ & $0.0108(6.15)^{* *}$ \\
\hline Compulsory service (years) & $0.0098(3.20)^{* *}$ & & & \\
\hline \multicolumn{5}{|l|}{1 if compulsory service } \\
\hline$<1$ year ago & & $0.0328(9.89)^{* *}$ & $0.0507(6.05)^{* *}$ & $0.0287(8.33)^{* *}$ \\
\hline 1 year ago & & $-0.0044(1.50)$ & $0.0152(2.12)^{*}$ & $-0.0067(2.15)^{*}$ \\
\hline 2 years ago & & $-0.0128(4.21)^{* *}$ & $0.0032(0.43)$ & $-0.0122(3.84)^{* *}$ \\
\hline 3 years ago & & $-0.0186(5.96)^{* *}$ & $-0.0022(0.29)$ & $-0.0178(5.44)^{* *}$ \\
\hline 4 years ago & & $-0.0157(4.91)^{* *}$ & $-0.0022(0.29)$ & $-0.0150(4.51)^{* *}$ \\
\hline 5 years ago & & $-0.0139(4.29)^{* *}$ & $-0.0093(1.20)$ & $-0.0117(3.44)^{* *}$ \\
\hline $6+$ years ago & & $-0.0204(9.46)^{* *}$ & $-0.0180(3.32)^{* *}$ & $-0.0186(8.20)^{* *}$ \\
\hline Year dummies & Yes & Yes & Yes & Yes \\
\hline Constant & $4.6295(683.91)^{* *}$ & $4.6195(655.89)^{* *}$ & $4.5326(261.17)^{* *}$ & $4.6441(627.11)^{* *}$ \\
\hline \# observations & 163,503 & 153,248 & 30,632 & 122,616 \\
\hline \# individuals & 11,000 & 11,000 & 1429 & 9571 \\
\hline$R^{2}$ & 0.39 & 0.36 & 0.54 & 0.31 \\
\hline$F(7,142,204)$ for ue & & 3.86 & & \\
\hline$p$ value & & 0.0003 & & \\
\hline$F(7,142,204)$ for ir & & 32.6 & & \\
\hline$p$ value & & 0.0 & & \\
\hline$F(7,142,204)$ for $n w$ & & 39.94 & & \\
\hline
\end{tabular}


Table 3 continued

\begin{tabular}{|c|c|c|c|c|}
\hline \multirow[t]{3}{*}{ Variables } & \multicolumn{2}{|c|}{ Quadratic model } & \multicolumn{2}{|c|}{ Segmented work history model ${ }^{a}$} \\
\hline & \multirow[t]{2}{*}{ Coef. (t value) } & \multirow[t]{2}{*}{ Coef. (t value) } & Female occupations & Integrated/male occupations \\
\hline & & & Coef. (t value) & Coef. (t value) \\
\hline p value & & 0.0 & & \\
\hline
\end{tabular}

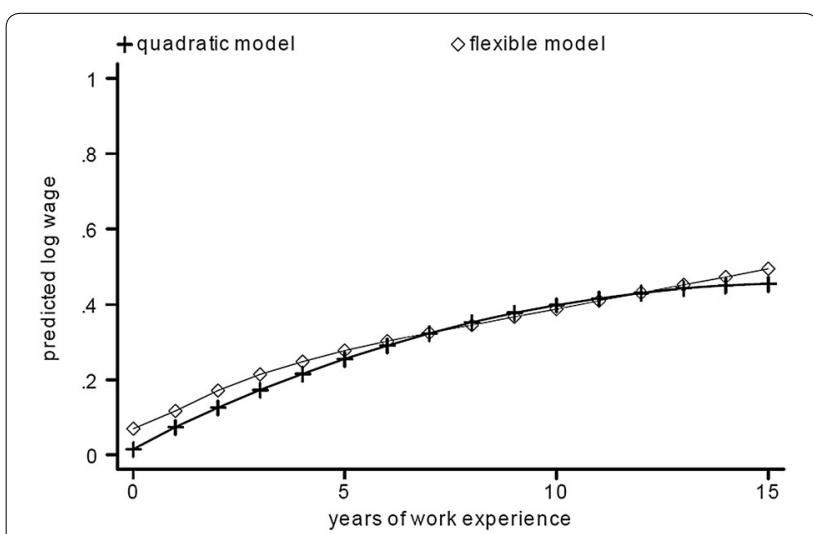

Fig. 1 Predicted wage-experience profile, males

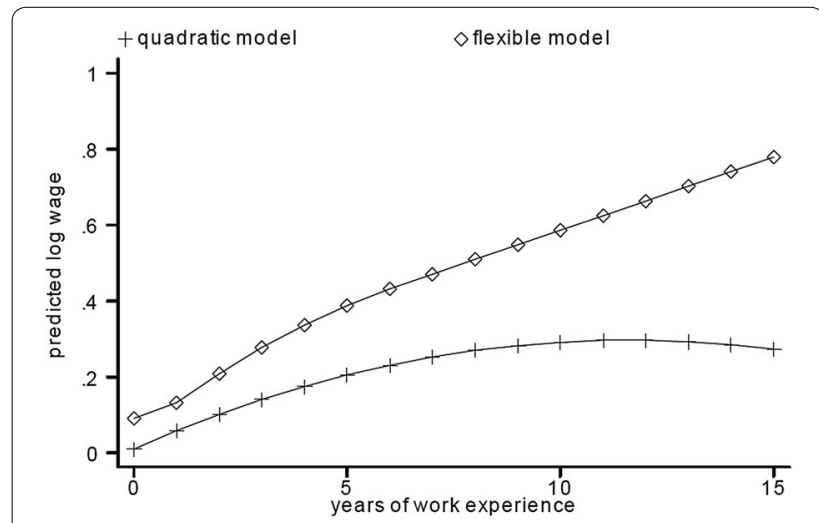

Fig. 2 Predicted wage-experience profile, females

and nurse. For skilled male workers, examples are motor vehicle mechanic, electrician, professional clerical worker, machinist, and joiner and pipe fitter. In fact, more than $60 \%$ of women are working in the above listed occupations. For men, concentration is less strong. In order to test whether human capital depreciation is low in "typical" female occupations, we re-estimate the previous models separately for female occupations and integrated/ male-dominated occupations, for men and women. The hypothesis in the Polachek (1981) model is then that wage losses for women in female-dominated occupations are smaller than in integrated and male dominated occupations, if human capital is driving wages. Approximately 120 occupations are distinguished in the data. We define that a female (-dominated) occupation is one where the fraction of female workers was $>60 \%$ in 1990 . All other occupations are summarized as integrated and male (-dominated) occupations. We report the results in columns 3 and 4 in Table 2 for women and Table 3 for men.

As column 3 in Tables 2 and 3 show, losses from work absences tend to be larger in the group of female-dominated occupations. For both male and female individuals, the short-term loss from unemployment is significant and negative in female-dominated occupations but not in integrated and male-dominated occupations. For women, losses from non-work are around 5\% in both occupation groups but appear to be more long-term in femaledominated occupations. For men, non-work seems to have slightly smaller negative effects on wages in femaledominated occupations than in others. Turning to the coefficients of maternity leave for women, we find that in female-dominated occupations the mean coefficients in the short and long term are very similar to the average levels that we found before. The wage loss because of maternity leave is approximately $30 \%$ smaller in integrated and male-dominated occupations than in the female-dominated occupations for women. These findings indicate that it is the workers in female-dominated occupations who lose in the short and long term relatively more from maternity leave and from work absence overall. This finding is not consistent with predictions from human capital theory. Women in male-dominated occupations are those who are better off. Our findings suggest that the negative coefficients must capture factors other than human capital depreciation, and women take other factors into account when sorting into occupations. The indicators for the two groups of occupations may capture other unobserved job characteristics.

We can also refute that differences across gender are explained by differences in the incidence of work absence; for example, that women are more likely to be unemployed for longer or to be not working. Looking back at the summary statistics in Table 1, women experience 
shorter periods of unemployment and non-work, or are less likely to be unemployed. ${ }^{27}$

\subsection{Firm mobility}

The relatively large effect of an interruption spell because of maternity leave may be the joint effect of depreciation and firm change, in the case where firm-specific human capital is an important component. The latter may add to the depreciation because the firm-specific human capital gained in the previous job cannot be used in the new job. In Table 4, we show that only a small proportion of women, approximately $22 \%$, change employer after maternity leave, and approximately $78 \%$ return to the previous employer. In columns 1 and 2 of Table 5 , the pooled estimation results for women are shown when we control for whether the firm of employment after the work absence is the same as before. While for those on maternity leave the option to return to the former employer is guaranteed, this is not the case for the unemployed and those reported as not working for other reasons. Indeed, we do find evidence consistent with the firm-specific capital hypothesis. In the short term, women who stayed with their employer after returning experienced a mean loss that was approximately $6 \%$ lower than in situations where they would have changed employer. ${ }^{28}$ If the maternity leave was longer than one year ago, however, the marginal effect of staying with the firm is noisy, negative or insignificant. If we look at men, then we note that for those who stay with the previous employer, the losses are relatively smaller or at least have not increased.

\subsection{Discussion of the results}

Our estimation results are based on skilled and highly attached men and women who are more similar than randomly selected men and women. One reason is that the population of skilled workers contains relatively more women working part-time or having work absence spells of several years, who are excluded from our sample. This explains why men and women in our sample are quite similar in terms of mean age and years of work experience. However, the work histories do reveal gender differences in our sample: women experience less unemployment than men but longer work interruptions (because of maternity leave), and men undertake compulsory service. Conditional on men and women being highly attached, we do find striking differences in the

\footnotetext{
${ }^{27}$ Note that women have, on average, shorter maternity leave than spells of unemployment.

28 Alternatively, it could also be related to time-varying unobserved fixed effects related to changes in the characteristics of the employer, occupation or sector. Women may, for example, switch to smaller firms, which we cannot control for in our data. Göggel and Zwick (2012) and Fitzenberger and Kunze (2005) show the importance of occupational mobility.
}

Table 4 Percentage employed with the same firm as before the period of absence from work, by gender

\begin{tabular}{lll}
\hline Comparison & Females & Males \\
\hline Before/after & & \\
Unemployment & $15.68 \%(487 / 3105)$ & $32.12 \%(3626 / 11290)$ \\
Non-work & $24.66 \%(1272 / 5159)$ & $26.26 \%(5056 / 19252)$ \\
Maternity leave & $78.81 \%(1837 / 2331)$ & \\
Compulsory service & & $82.74 \%(3734 / 4513)$ \\
\hline
\end{tabular}

In parentheses we report the number of observations for those who return to the firm (employer) where they worked before the period of absence and the total number of observations for which the type of absence is reported. We distinguish four types of absences: unemployment, interruption due to parental leave, interruption due to compulsory service and non-work (residual group)

effects of different types of work absence on wages estimated by a fixed-effects model.

The results suggest further questions, particularly regarding the effects of work interruptions and maternity leave. One may argue that compulsory military service is exogenous (see Acemoglu and Pischke 1998). Having a child and the timing of childbirth is potentially endogenous, and the decisions regarding how long to remain on maternity leave and whether to return are complex decisions. ${ }^{29}$ Overall, we find negative effects of maternity leave on wages, which is consistent with human capital explanations. The finding of relatively large negative wage effects of maternity leave in female-dominated occupations appears, however, to be inconsistent with human capital explanations. Human capital theory would predict relatively small negative effects in female-dominated occupations for women. This suggests that other mechanisms are at work. Felfe (2012) suggests a compensating wage argument related to job amenities. Women may be willing to accept wage cuts at the mean in return for more flexible working conditions. If women who return to full-time work are more likely to return in femaledominated occupations and flexible working conditions are more likely in female-dominated occupations, then this could explain our findings.

\section{Conclusions}

In this paper, we use a sample of young skilled highly attached workers covering an important part of the West German labour market to study the short- and long-term wage effects of work absences. Workers are observed from first entry into the labour market after completion of vocational training and followed over a period up to

\footnotetext{
${ }^{29}$ We acknowledge that our study does not account for potential household effects following maternity leave. The relatively large negative coefficient of the maternity leave variable may also have other explanations such as a penalty for motherhood or statistical discrimination. We also cannot rule out the possibility of small reductions in monthly hours after childbirth or effects through fatigue and even psychological distress because of additional responsibilities and overall workload with the birth of the child (Boye 2010).
} 
Table 5 Fixed effects estimates of time out work variables in the wage equations 1981-1997 IABS data

\begin{tabular}{|c|c|c|c|c|}
\hline \multirow[t]{3}{*}{ Variables } & \multicolumn{2}{|c|}{ Female sample estimates } & \multicolumn{2}{|c|}{ Male sample estimates } \\
\hline & & FIRMSTAYER interacted with variables & & FIRMSTAYER interacted with variables \\
\hline & Coef. (t value) & Coef. (t value) & Coef. (t value) & Coef. (t value) \\
\hline \multicolumn{5}{|c|}{1 if in unemployment } \\
\hline$<1$ year ago & $-0.0205(3.40)^{* *}$ & $0.0398(3.34)^{* *}$ & $-0.0126^{*}(4.23)^{*}$ & $0.0413(8.94)^{* *}$ \\
\hline 1 year ago & $0.0035(0.35)$ & $-0.0199(1.76)$ & $0.0108^{*}(2.63)^{*}$ & $-0.0219(4.59)^{* *}$ \\
\hline 2 years ago & $-0.0019(0.20)$ & $0.0067(0.61)$ & $-0.0023(0.56)$ & $-0.0021(0.43)$ \\
\hline 3 years ago & $0.0070(0.66)$ & $0.0008(0.07)$ & $-0.0009(0.20)$ & $-0.0037(0.73)$ \\
\hline 4 years ago & $-0.0192(1.63)$ & $0.0189(1.44)$ & $0.0108(2.27)^{*}$ & $-0.0115(2.12)^{*}$ \\
\hline 5 years ago & $0.0022(0.17)$ & $-0.0028(0.20)$ & $0.0020(0.40)$ & $-0.0009(0.15)$ \\
\hline $6+$ years ago & $0.0101(1.08)$ & $-0.0121(1.22)$ & $-0.0174^{*}(4.27)^{*}$ & $0.0104(2.39)^{*}$ \\
\hline \multicolumn{5}{|l|}{1 if in non-work } \\
\hline$<1$ year ago & $-0.0591(11.10)^{* *}$ & $0.0357(4.30)^{* *}$ & $-0.0201(8.16)^{* *}$ & $0.0281(7.17)^{* *}$ \\
\hline 1 year ago & $-0.0182(2.11)^{*}$ & $-0.0395(4.16)^{* *}$ & $-0.0064(1.86)$ & $-0.0097(2.48)^{*}$ \\
\hline 2 years ago & $-0.0289(3.57)^{* *}$ & $-0.0156(1.70)$ & $-0.0108(3.26)^{* *}$ & $0.0043(1.12)$ \\
\hline 3 years ago & $-0.0204(2.29)^{*}$ & $-0.0120(1.21)$ & $-0.0127(3.56)^{* *}$ & $0.0079(1.96)^{*}$ \\
\hline 4 years ago & $-0.0278(2.95)^{* *}$ & $-0.0015(0.14)$ & $-0.0072(1.89)$ & $0.0039(0.91)$ \\
\hline 5 years ago & $-0.0163(1.62)$ & $-0.0011(0.10)$ & $-0.0041(1.05)$ & $0.0087(1.96)$ \\
\hline $6+$ years ago & $-0.0096(1.20)$ & $0.0171(2.02)^{*}$ & $-0.0083(2.40)^{*}$ & $0.0185(5.03)^{* *}$ \\
\hline \multicolumn{5}{|c|}{1 if maternity leave } \\
\hline$<1$ year ago & $-0.2305(22.33)^{* *}$ & $0.0599(5.47)^{* *}$ & & \\
\hline 1 year ago & $-0.1450(9.13)^{* *}$ & $-0.0350(2.11)^{*}$ & & \\
\hline 2 years ago & $-0.1446(10.02)^{* *}$ & $-0.0042(0.27)$ & & \\
\hline 3 years ago & $-0.0955(5.88)^{* *}$ & $-0.0522(3.03)^{* *}$ & & \\
\hline 4 years ago & $-0.1557(8.56)^{* *}$ & $0.0108(0.56)$ & & \\
\hline 5 years ago & $-0.0954(5.02)^{* *}$ & $-0.0421(2.08)^{*}$ & & \\
\hline $6+$ years ago & $-0.1063(7.47)^{* *}$ & $-0.0309(2.10)^{*}$ & & \\
\hline \multicolumn{5}{|l|}{ Constant } \\
\hline \multicolumn{5}{|c|}{1 if compulsory service } \\
\hline$<1$ year ago & & & $0.0138(2.09)^{*}$ & $0.0138(1.95)$ \\
\hline 1 year ago & & & $-0.0113(1.50)$ & $0.0089(1.11)$ \\
\hline 2 years ago & & & $-0.0251(3.61)^{* *}$ & $0.0151(2.01)^{*}$ \\
\hline 3 years ago & & & $-0.0284(3.93)^{* *}$ & $0.0117(1.49)$ \\
\hline 4 years ago & & & $-0.0231(3.10)^{* *}$ & $0.0092(1.14)$ \\
\hline 5 years ago & & & $-0.0165(2.11)^{*}$ & $0.0032(0.38)$ \\
\hline $6+$ years ago & & & $-0.0218(4.64)^{* *}$ & $0.0017(0.34)$ \\
\hline Constant & & $4.4636(374.53)^{* *}$ & & $4.6143(654.19)^{* *}$ \\
\hline \# observations & & 72,679 & & 153,248 \\
\hline \# individuals & & 5753 & & 11,000 \\
\hline$R^{2}$ & & 0.31 & & 0.36 \\
\hline
\end{tabular}

All regressions include year dummies

* Significant at $5 \%$ level; ** significant at $1 \%$ level

15 years. Complete employment and wage history data from the register data are used for the period from 1975 to 1997 . We present results from panel wage regressions estimated by fixed effects.

We find varying effects on wages across types of work absence and varying long-term patterns. Overall, the wage effects of all types of absence are negative in the short term, except for compulsory service for men. Compulsory service has positive short-term effects but small and complex effects in the longer term. The positive effect may suggest that at the mean, skilled workers acquire some general skills during compulsory service. Examples 
of such skills are soft skills and ability to work in a hierarchical organization. The negative effect of unemployment on wages is only significant in the very short term and is relatively stronger for women than for men. As we do not find significant long-term effects, no scarring effect is found for skilled female and male workers. Maternity leave leads to substantial wage losses for women. Notably, these losses also seem to be large in the longer term. A notable finding is that maternity leave leads to substantially higher wage losses than other types of work absence, especially in the long term. This finding illustrates that the wage losses that women suffer after giving birth cannot be explained merely by general time away from work.

\section{Acknowlegements}

We thank the IAB for providing data access via a Scientific Use File to the anonymous IABS 75-97. This is a revised version of the paper circulated under the title "The timing of careers and human capital depreciation". For discussions and comments on the revised paper, the author thanks Ana Rute Cardoso, Øivind Anti Nilsen, Niklas Potrafke, Uta Schönberg and Regina Riphahn.

\section{Competing interests}

The author declares that she has no competing interests.

\section{Publisher's Note}

Springer Nature remains neutral with regard to jurisdictional claims in published maps and institutional affiliations.

Received: 24 February 2017 Accepted: 5 May 2017

Published online: 25 September 2017

\section{References}

Acemoglu, D., Pischke, S.: Why do firms train? Theory and evidence. Q. J. Econ. 113, 79-119 (1998)

Albrecht, J.W., Edin, P.A., Sundström, M., Vroman, S.B.: Career interruptions and subsequent earnings: a reexamination using Swedish data. J. Hum. Resour. 34(2), 294-311 (1999)

Anderson, D.J., Binder, M., Krause, K.: The motherhood wage penalty: Which mothers pay it and why? Am. Econ. Rev. 92(2), 354-358 (2002)

Arulampalam, W., Gregg, P., Gregory, M.: Unemployment scarring. Econ. J. $\mathbf{1 1 1}(475), 577-584(2001)$

Arulampalam, W.: Is unemployment really scarring? Effects of unemployment experiences on wages. Econ. J. 111(475), 585-606 (2001)

Bauer, T., Bender, S., Paloyo, A.R., Schmidt, C.M.: Evaluating the labor-market effects of compulsory military service. Eur. Econ. Rev. 56, 814-829 (2012)

Beblo, M., Bender, S., Wolf, E.: Establishment-level wage effects of entering motherhood. Oxf. Econ. Pap. 61, i1 1-i34 (2009)

Bender, S., Haas, A., Klose, C.: The IAB employment subsample 1975-1995. J. Appl. Soc. Sci. Stud. 120(4), 649-662 (2000)

Boye, K.: Time spent working: paid work, housework and the gender difference in psychological distress. Eur. Soc. 12(3), 419-442 (2010)

Budig, M.J., England, P.: The wage penalty for motherhood. Am. Sociol. Rev. $\mathbf{6 6}(2), 204-225(2001)$

Buligescu, B., de Crombrugghe, D., Mentesoglu, G., Montizaan, R.: Panel estimates of the wage penalty for maternal leave. Oxf. Econ. Pap. $\mathbf{6 1}$ (suppl 1), i35-i55 (2009)

Card, D., Cardoso, A.R.: Can compulsory military service raise civilian wages? Evidence from the peacetime draft in Portugal. Am. Econ. J. 4(4), 57-93 (2012)

Ejrnæs, M. and A. Kunze (2006): What is driving the family gap in women's wages? Norwegian School of Economics and Business Administration, mimeo

Ejrnæs, M., Kunze, A.: Work and wage dynamics around childbirth. Scand. J. Econ. 115(3), 856-877 (2013)
England, P.: The failure of human capital theory to explain occupational sex segregation. J. Hum. Resour. 17(3), 358-370 (1982)

Felfe, C.:The motherhood wage gap: what about job amenities? Labour Econ. 19(1), 59-67 (2012)

Gupta, N.D., Smith, N.: Children and career interruptions: the family gap in Denmark. Economica 69, 609-629 (2002)

Fitzenberger, B., Kunze, A.: Vocational training and gender: wages and occupational mobility among young workers. Oxf. Rev. Econ. Policy 21 (3), 392-415 (2005)

Göggel, K., Zwick, T.: Heterogeneous wage effects of apprenticeship training. Scand. J. Econ. 114(3), 756-779 (2012)

Gregg, P., Tominey, E.: The wage scar from male youth unemployment. Labour Econ. 12(4), 487-492 (2005)

Gregory, M., Jukes, R.: Unemployment and subsequent earnings: estimating scarring among British men 1984-94. Econ. J. 111(475), F607-F625 (2001)

Görlich, D., de Grip, A.: Human capital depreciation during hometime. Oxf. Econ. Pap. 61(suppl 1), i98-i121 (2009)

Joshi, H., Paci, P., Waldfogel, J.: The wages of motherhood: better or worse? Cambridge J. Econ. 23(5), 543-564 (1999)

Kim, M.K., Polachek, S.W.: Panel estimates of male-female earnings functions. J. Hum. Res. 29(2), 406-428 (1994)

Kletzer, L., Fairlie, R.W.: The long-term costs of job displacement for young adult workers. ILR Rev. 56, 682-698 (2003)

Kuhn, P.: Losing work, moving on: Worker displacement in international perspective. WE Upjohn Institute for Employment Research, Kalamazoo (2002)

Kunze, A.: The evolution of the gender wage gap. Labour Econ. 12, 73-97 (2005)

Light, A., Ureta, M.: Early-career work experience and gender wage differentials. J. Labor Econ. 13(1), 121-154 (1995)

Miller, A.R.: The effects of motherhood timing on career path. J. Popul. Econ. 24(3), 1071-1100 (2011)

Mincer, J.: Schooling, experience and earnings. Columbia University, New York (1974)

Mincer, J., Ofek, H.: Interrupted work careers: depreciation and restoration of human capital. J. Hum. Resour. 17, 3-24 (1982)

Mincer, J., Polachek, S.W.: Family investment in human capital: earnings of women. J. Polit. Econ. 82, S76-S108 (1974)

Möller, J., Umkehrer, M.: Are there long-term earnings scars from youth unemployment in Germany? Jahrbücher für Nationalökonomie und Statistik 235(4-5), 474-498 (2015)

Nielsen, H.S., Simonsen, M., Verner, M.: Does the gap in family-friendly policy drive the family gap? Scand. J. Econ. 106(4), 721-744 (2004)

Nilsen, Ø.A., Reiso, K.H.: Scarring effects of early-career unemployment. Nord. Econ. Policy Rev. 1, 13-45 (2011)

Ondrich, J.C., Spiess, K., Yang, Q., Wagner, G.: The liberalization of maternity leave policy and the return to work after childbirth in Germany. Rev. Econ. Househ. 1, 77-110 (2003)

Phipps, S., Burton, P., Lethbridge, L.: In and out of labour market: long-term income consequences of child-related interruptions to women's paid work. Can. J. Econ. 34(2), 411-429 (2001)

Polachek, S.W.: Occupational self-selection: a human capital approach to sex differences in occupational structure. Rev. Econ. Stat. 63(1), 60-69 (1981)

Schmieder, J.F., von Wachter, T., Bender, S.: The effects of extended unemployment insurance over the business cycle: evidence from regression discontinuity estimates over 20 years. Q. J. Econ. 127(2), 701-752 (2012)

Schönberg, $\mathrm{U}$ : Does the IAB employment sample reliably identify maternity leave taking? A data report, Zeitschrift fuer Arbeitsmarktforschung. 42 , 49-70 (2009)

Schönberg, U., Ludsteck, J.: Expansions in maternity leave coverage and mothers'labor market outcomes after childbirth. J. Labor Econ. 32, 469-505 (2014)

Trabold, H., Schneider, T., Vogel, P.: Wehrpflicht- statt Berufsarmee: Eine Alternative wider die ökonomische Vernunft. Perspektiven der Wirtschaftspolitik 7(1), 127-142 (2006)

Viitanen, T.: The motherhood wage gap in the U.K. over the life cycle. Rev. Econ. Househ. 12(2), 259-276 (2014)

Waldfogel, J.:The family gap for young women in the United States and Britain: can maternity leave make a difference? J. Labor Econ. 16(3), 505-545 (1998) 